\title{
Homeostatic and Nonhomeostatic Modulation of Learning in Human Motor Cortex
}

\author{
Patrick Jung and Ulf Ziemann \\ Department of Neurology, Goethe University Frankfurt, 60528 Frankfurt am Main, Germany
}

\begin{abstract}
Motor learning is important throughout life for acquisition and adjustment of motor skill. The extent of motor learning may be modulated by the history of motor cortex activity, but little is known which metaplasticity rule (homeostatic vs nonhomeostatic) governs this interaction. Here, we explored in nine healthy adults the effects of three different paired associative stimulation (PAS) protocols on subsequent learning of rapid thumb flexion movements. PAS resulted in either a long-term potentiation (LTP)-like increase in excitability of the stimulated motor cortex $\left(\mathrm{PAS}_{\mathrm{LTP}}\right)$, or a long-term depression (LTD)-like decrease $\left(\mathrm{PAS}_{\mathrm{LTD}}\right)$, or no change (control condition, $\mathrm{PAS}_{\mathrm{CON}}$ ). Learning was indexed by the increase in peak acceleration of the trained movement. Delays of 0 and 90 min between PAS and motor practice were tested. At the 0 min delay, PAS $_{\text {LTD }}$ strongly facilitated motor learning (homeostatic interaction), and PAS ${ }_{\text {LTP }}$ also facilitated learning, although to a lesser extent (nonhomeostatic interaction). At the $90 \mathrm{~min}$ delay, $\mathrm{PAS}_{\mathrm{LTD}}$ facilitated learning, whereas PAS $_{\text {LTP }}$ depressed learning (interactions both homeostatic). Therefore, facilitation of learning by previous brain stimulation occurs primarily and most effectively through homeostatic interactions, but at the 0 min delay, nonhomeostatic mechanisms such as LTPinduced blockade of LTD and nonsaturated LTP-induced facilitation of learning might also play a role. The present findings demonstrate that motor learning in humans can be modulated by noninvasive brain stimulation and suggest the possibility of enhancing motor relearning in defined neurological patients.
\end{abstract}

\section{Introduction}

Motor learning is of crucial importance throughout life for acquisition of new skills and reacquisition of formerly known but, attributable to brain lesion, lost skills (Sanes, 2003; Krakauer, 2006). There is now substantial evidence that many types of motor learning occur in the primary motor cortex (M1) and involve synaptic plasticity in the form of long-term potentiation (LTP) (Rioult-Pedotti et al., 2000; Monfils and Teskey, 2004). It served as a central argument for this assertion that, in rat M1, less LTP but more long-term depression (LTD) could be induced if M1 was engaged in recent motor skill learning compared with a nontraining condition (Rioult-Pedotti et al., 1998, 2000; Monfils and Teskey, 2004). In humans, long-term excitability change of M1 can be induced by paired associative stimulation (PAS), a noninvasive and painless transcranial magnetic stimulation (TMS) protocol (Stefan et al., 2000, 2002; Wolters et al., 2003; Müller et al., 2007). This excitability change is termed LTP/LTD-like because it shares major properties of LTP/LTD studied at the cellular level, such as cooperativity, associativity, input-specificity, and dependence on activation of NMDA receptors (Cooke and Bliss, 2006; Ziemann et al., 2008). Similar to the rat, motor skill

Received Jan. 15, 2009; revised March 13, 2009; accepted April 1, 2009

This work was supported by Grants ZI 542/4-1 and ZI 542/4-2 from the German Research Foundation (Deutsche Forschungsgemeinschaft) to U.Z. We thank Prof. John Rothwell for advice on parts of the data analysis (trial-by-trial variability of peak acceleration).

Correspondence should be addressed to Prof. Ulf Ziemann, Motor Cortex Group, Department of Neurology, Goethe University Frankfurt, Schleusenweg 2-16, 60528 Frankfurt am Main, Germany. E-mail: u.ziemann@em.uni-frankfurt.de.

DOI:10.1523/JNEUROSCI.0222-09.2009

Copyright $\odot 2009$ Society for Neuroscience $\quad$ 0270-6474/09/295597-08\$15.00/0 learning decreases subsequent PAS-induced LTP-like plasticity but increases LTD-like plasticity of the trained M1 (Ziemann et al., 2004; Stefan et al., 2006; Rosenkranz et al., 2007). This learning-dependent bidirectional modification of LTP/LTD-like plasticity is consistent with homeostatic metaplasticity, an important concept for maintaining overall synaptic weight and firing rate in a neuronal network within the physiological range (Abraham and Bear, 1996; Abbott and Nelson, 2000; Turrigiano and Nelson, 2004).

It is an important but thus far untested question to which extent PAS can enhance subsequent motor learning and whether or not homeostatic metaplasticity governs this interaction. Recent work showed that motor learning can be influenced by brain stimulation. Findings varied between homeostatic, nonhomeostatic, and lack of interaction with different types of brain stimulation (regular repetitive TMS, theta burst stimulation, transcranial direct current stimulation), learning tasks (repeated simple movements, sequential finger movements, serial reaction time task, visuo-motor tracking), and timings of brain stimulation relative to practice (consecutive, concurrent) (Nitsche et al., 2003; Boggio et al., 2006; Agostino et al., 2007, 2008; Antal et al., 2008; Kuo et al., 2008; Vines et al., 2008). Thus, a clear picture has not yet emerged.

Here, we tested for the first time interactions of PAS with subsequent motor learning. According to the known effects of motor learning on subsequent PAS-induced plasticity (Ziemann et al., 2004; Stefan et al., 2006; Rosenkranz et al., 2007), we expected homeostatic interactions, i.e., LTP-like plasticity to depress subsequent motor learning and LTD-like plasticity to enhance it. Furthermore, as timing likely plays an important role 
(Nitsche et al., 2003, 2007; Kuo et al., 2008; Ziemann and Siebner, 2008), we investigated two delays (0 min vs $90 \mathrm{~min}$ ) between PAS and subsequent motor practice to determine the time course of PAS effects on motor learning.

\section{Materials and Methods}

Subjects. Nine healthy subjects (two female; mean age, $28.2 \pm 4.9$ years) participated in experiment 1 , and nine partially different healthy subjects (five female; mean age, $30.9 \pm 6.2$ years) were tested in experiment 2 . None of the subjects had a history of neurological or psychiatric disease, and no one was on CNS-active medication at the time of the experiments. All subjects were nonsmokers, and all were right handed with a mean laterality index of $98.7 \pm$ $4.0 \%$ (range, $88-100 \%$ ) in experiment 1 and $97.1 \pm 5.8 \%$ (range, $86-100 \%$ ) in experiment 2, according to the Edinburgh Inventory (Oldfield, 1971). All gave written informed consent. The experiments conformed to the declaration of Helsinki and were approved by the ethics committee of the University Hospital Frankfurt.

Time line of experiments. The general time line of experiments 1 and 2 is displayed in Figure 1 and will be explained in detail in the following paragraphs. Experiments 1 and 2 are similar but differ in one important detail which is the delay between PAS and the subsequent two blocks of motor practice: immediate in experiment 1 versus $90 \mathrm{~min}$ in experiment 2 .

PAS. PAS consisted of 225 electrical stimuli applied to the right median nerve at the wrist, paired with TMS of the hand area of the left M1 at the hot spot optimal for eliciting motor evoked potentials (MEPs) in the right flexor pollicis brevis (FPB) muscle. The rate of paired stimulation was $0.25 \mathrm{~Hz}$ (i.e., duration of PAS, $15 \mathrm{~min}$ ). Electrical stimulation was applied through a bipolar electrode (cathode proximal), using constant current square wave pulses (duration, $1 \mathrm{~ms}$ ) at an intensity just above motor threshold to elicit a small $(<200 \mu \mathrm{V})$ M wave. TMS was delivered through a focal figure-eight coil (diameter of each wing, $70 \mathrm{~mm}$ ) connected to a Magstim 200 magnetic stimulator with a near monophasic current waveform (The Magstim Company). The coil was held tangential to the scalp with the handle pointing backwards and $45^{\circ}$ away from the midline. This way, the induced current in the brain is directed from lateral-posterior to medial-anterior, an orientation leading to predominantly transsynaptic activation of the corticospinal neurons via horizontal corticocortical connections (Di Lazzaro et al., 2004, 2008). The intensity of TMS was adjusted to produce MEPs of $\sim 1 \mathrm{mV}$ in peak-to-peak amplitude in the resting FPB when given without the preceding median nerve stimulus. MEPs were recorded from the FPB by surface electromyography (EMG), using $\mathrm{Ag}-\mathrm{AgCl}$ cup electrodes in a belly-tendon montage. The EMG raw signal was amplified and filtered $(0.05-2 \mathrm{kHz}$, Counterpoint Mk2 Electromyograph; Dantec), digitized (A/D rate 5 $\mathrm{kHz}$, Micro 1401; Cambridge Electronic Design) and fed into a laboratory computer for online visual display and off-line analysis.

Three interstimulus intervals between the median nerve stimulus and TMS were tested in separate sessions. One exceeded the individual N20 cortical component of the right median nerve somatosensory evoked potential by $2 \mathrm{~ms}$, one interval was shorter by $5 \mathrm{~ms}$ than the N20 latency, and the third interval was set to $100 \mathrm{~ms}$. These intervals were selected because previous experiments showed consistently that the interval of $\mathrm{N} 20+2 \mathrm{~ms}$ results in a long-lasting LTP-like MEP increase, whereas the interval of N20 - 5 ms leads to a LTD-like MEP decrease, and the interval of $100 \mathrm{~ms}$ does not produce significant change (Stefan et al., 2000; Ziemann et al., 2004; Müller et al., 2007). Therefore, the latter served as a control $(\mathrm{CON})$ condition and will be referred to as $\mathrm{PAS}_{\mathrm{CON}}$, whereas the other two conditions will be referred to as $\mathrm{PAS}_{\mathrm{LTP}}$ and PAS $\mathrm{LTD}_{\text {}}$, respec- tively. In both experiment 1 and experiment 2, each subject was tested for all three PAS conditions in a pseudo-randomized balanced double-blind controlled crossover design. The minimum delay between subsequent sessions in a given subject was 1 week. The PAS interstimulus interval was set by an additional experimenter not involved otherwise in the experiment or data analysis. Therefore, primary experimenter and subject were blinded toward the PAS condition.

Quantification of PAS effects. MEP amplitudes were measured in the right FPB to assess changes in corticospinal excitability of the hand area of the left M1 induced by PAS. The FPB was selected as EMG target muscle because it serves as the primary mover of the motor practice task (see below). MEP amplitude reflects synaptic excitability in M1 regulated by various inhibitory and excitatory neurotransmitter systems ( $\mathrm{Zi}$ emann, 2004). In addition, MEP amplitude may be affected by excitability changes of spinal motoneurons, but the majority of previous studies provided consistent and convergent evidence that changes in MEP amplitude induced by PAS occur mainly or exclusively at the cortical level (Stefan et al., 2000; Ridding and Taylor, 2001; Wolters et al., 2003; Kujirai et al., 2006). MEPs were elicited in the relaxed FPB of the right hand by TMS applied to the hot spot of the left M1 hand area (see above). Relaxation of the FPB was monitored by providing high-gain $(50 \mu \mathrm{V} /$ division $)$ online audio-visual feedback of the EMG raw signal. Trials contaminated with voluntary EMG activity were discarded from analysis. Time points of MEP measurements (experiment 1: B0, B1; experiment 2: B0, B1, B2) are shown in Figure 1. At B0, TMS intensity was adjusted to elicit MEPs of on average $1 \mathrm{mV}$ in peak-to-peak amplitude $\left(\mathrm{MEP}_{1 \mathrm{mV}}\right)$. At each time point of MEP measurements, 20 MEPs were obtained, using a mean intertrial interval of $10 \mathrm{~s}$ with a random intertrial interval variation of $25 \%$ to reduce anticipation of the next trial. For each subject, time point, and PAS condition, the single-trial peak-to-peak MEP amplitudes were averaged and normalized to the MEP amplitude measured at B0 (compare Fig. 2).

Motor practice. Subjects were seated in a comfortable chair. Their right arm was held in an adducted position in the shoulder and an $\sim 90^{\circ}$ flexed position in the elbow. The forearm was in a semipronated position and rested on a plate. Forearm, wrist, and fingers II-V were tightly fixed in a cast, leaving the thumb free for movements in all directions. The learning task was adopted from previous studies (Muellbacher et al., 2001; Ziemann et al., 2004; Agostino et al., 2007, 2008; Walther et al., 2008) and 

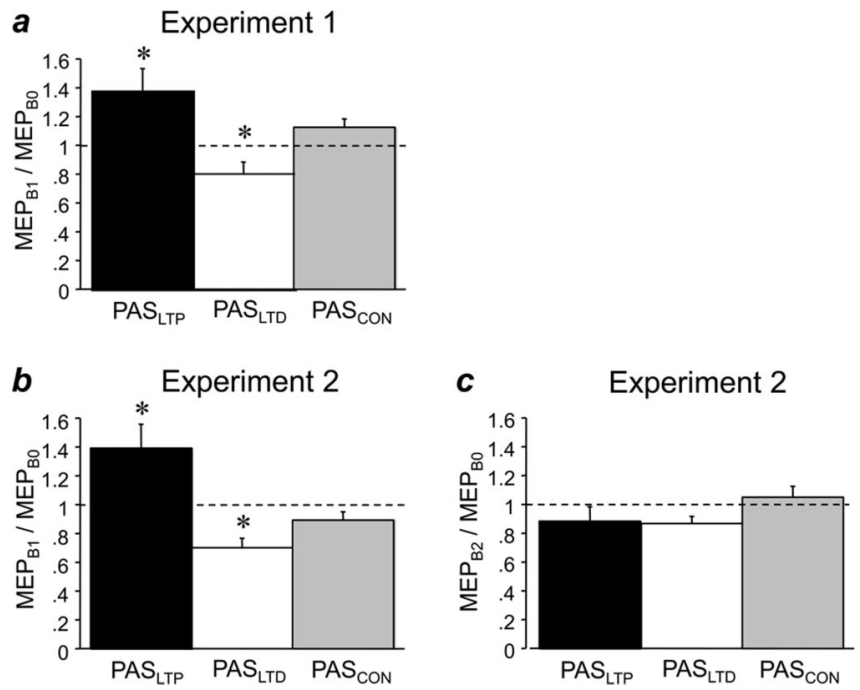

Figure 2. Effects of PAS on MEP amplitude. $\boldsymbol{a}$, In experiment 1, PAS in significant MEP increase (MEPs measured at time point $B 1$ immediately after $P A S$, normalized

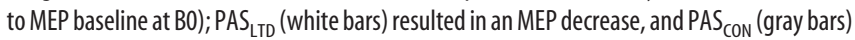
led to no change. $\boldsymbol{b}$, In experiment 2 , findings were essentially identical to experiment 1 when MEP at time point B1 was compared with baseline at B0. c, In experiment 2, when MEPs after 90 min waiting (time point $B 2$ ) were compared with baseline at $B 0$, all of the changes in $\boldsymbol{b}$ were no longer present. All data are means of nine subjects; error bars are $1 \mathrm{SEM}$. Asterisks indicate significant difference from 1 (one-sample two-tailed $t$ tests, $p<0.05$ ).

consisted of fastest flexion movements in the metacarpo-phalangeal joint of the right thumb for two blocks of $15 \mathrm{~min}$, paced by a brief 1000 $\mathrm{Hz}$ tone at a rate of $0.25 \mathrm{~Hz}$. This relatively low rate was used to prevent muscle fatigue. Before each movement, the thumb had to return as accurately as possible into a horizontal resting position indicated by a pointer. This prevented shifts of the thumb starting position during practice as a possible unspecific cause for performance improvement. The two blocks of motor practice were separated by $5 \mathrm{~min}$ to obtain one block of acceleration (ACC) measurements (time point P1) (compare Fig. 1 and Quantification of learning, see below). Acceleration of the thumb movements was measured by one uniaxial accelerometer (Model 2256A100 , voltage sensitivity $100 \mathrm{mV} / \mathrm{g}$; Endevco), mounted on the dorsal aspect of the proximal phalanx of the thumb to detect movement in the flexion-extension axis. The raw signal was amplified (Model 133 signal conditioner; Endevco), digitized (A/D rate $5 \mathrm{kHz}, \mathrm{CED}$ Micro 1401) and fed into the laboratory computer for online visual display and off-line analysis. Subjects were encouraged by the experimenter throughout the experiment to perform fastest possible and isolated thumb flexion movements. Performance was fed back to the subject throughout motor practice and during all acceleration measurements (compare Fig. 1, ACC) by plotting peak acceleration of the actual trial and the course of peak acceleration of all previous trials from the same block of trials on the screen in front of the subject.

Quantification of learning. Repeated fastest finger movements lead rapidly to an increase in peak acceleration of the trained movement (Muellbacher et al., 2001, 2002; Ziemann et al., 2004; Walther et al., 2008). Accordingly, learning was quantified by comparing the mean first peak acceleration of 20 externally paced $(1000 \mathrm{~Hz}$ tone at a rate $0.25 \mathrm{~Hz})$ fastest possible thumb flexion movements measured between (Fig. 1, time point $\mathrm{P} 1$ ) and for $30 \mathrm{~min}$ after the two blocks of motor practice (Fig. 1, time points P2-P5) with those at baseline immediately before the first block of motor practice (time point B1 in experiment 1 , time point B2 in experiment 2) (Fig. 1). In addition, peak acceleration was measured throughout the two blocks of motor practice $(2 \times 225$ thumb flexion movements). For analysis, peak accelerations during practice were binned in periods of $1 \mathrm{~min}$, averages of the peak accelerations from the 15 movements in each bin were calculated and normalized to the mean peak acceleration at baseline (time point B1 or B2 in experiments 1 and 2, respectively) (compare Fig. 3).
Quantification of trial-by-trial variability of peak acceleration. It is possible that the differential effects of the PAS conditions on motor learning (see Results) have been the consequence of adopting different learning strategies during practice. Probably, the most important factor is trialby-trial variability of the outcome measure, the peak acceleration of the trained movement. Differences in trial-by-trial variability between PAS conditions would indicate that subjects adopted different learning rules: small variability would mean that information from previous trials is used consistently to optimize the trained movement in the sense of an asymptotic approach to the optimum, whereas large variability would indicate that this information is less consistently used and that "escape trials" occur away from the iterative performance pathway to enable sudden improvement steps. Trial-by-trial analysis was performed for the 225 trials of each of the two blocks of motor practice. The improvement of peak acceleration with practice was modeled by defining an implicit "target" that was calculated as follows: starting with the second trial, peak acceleration in each trial was tested for whether it exceeded the previous target: if so, then this target was increased by $50 \%$ of the difference between the new maximum peak acceleration and the old target; if not, then the old target remained unchanged. This reflects the strategy to maximize performance by using the memory of what has been achieved in previous trials and does not impose any preformed learning rule onto the analysis. The value of $50 \%$ was chosen to curtail the effect of isolated outliers. Then, for each trial, the difference between the actual peak acceleration and the current target was calculated, and the mean and SD of these differences from target were determined for the whole-motor practice session in bins of $1 \mathrm{~min}$, and the coefficients of variability were calculated as SD divided by the mean. Importantly, these values are unaffected by the magnitude of baseline performance or overall change induced by practice.

Data analysis and statistics. PAS effects on MEP amplitude, peak acceleration, and coefficient of variation of peak acceleration were assessed separately for experiment 1 and experiment 2 by using repeatedmeasures (rm) ANOVA. Post hoc comparisons were performed in case of significant rmANOVA effects using Fisher's PLSD. Significance was assumed if $p<0.05$. Data are given as means \pm 1 SEM.

\section{Results}

Preliminary data of two subjects of experiment 1 have been reported previously (Ziemann et al., 2006).

All subjects tolerated the experimental procedures well without adverse effects.

\section{Experiment 1}

\section{PAS effects on MEP amplitude}

RmANOVA showed that PAS condition had a significant effect on MEP amplitude $\left(F_{(2,8)}=10.14, p=0.0014\right)$, and post hoc tests revealed that $\mathrm{PAS}_{\mathrm{LTP}}$ resulted in a significant increase in MEP amplitude $\left(\mathrm{MEP}_{\mathrm{B} 1} / \mathrm{MEP}_{\mathrm{B} 0}: 1.38 \pm 0.16, t=2.35, p=0.047\right)$; PAS $_{\text {LTD }}$ led to a significant MEP decrease $(0.80 \pm 0.08, t=-2.53$, $p=0.036)$, whereas PAS $_{\mathrm{CON}}$ had no significant effect $(1.12 \pm$ $0.07, p>0.05$ ) (Fig. 2a). MEP amplitudes at baseline (time point $\mathrm{B} 0$ ) were not different across PAS conditions and, therefore, cannot account for the different PAS effects $\left(\mathrm{PAS}_{\mathrm{LTP}}, 1.14 \pm 0.08\right.$ $\left.\mathrm{mV} ; \mathrm{PAS}_{\mathrm{LTD}}, 1.35 \pm 0.05 \mathrm{mV} ; \mathrm{PAS}_{\mathrm{CON}}, 1.23 \pm 0.08 \mathrm{mV}\right)$.

\section{PAS effects on peak acceleration before motor practice}

None of the PAS conditions exerted any significant effect on the peak acceleration of thumb flexion movements before motor practice $\left(\mathrm{ACC}_{\mathrm{B} 1} / \mathrm{ACC}_{\mathrm{B} 0}, \mathrm{PAS}_{\mathrm{LTP}}, 0.98 \pm 0.07 ; \mathrm{PAS}_{\mathrm{LTD}}, 0.94 \pm\right.$ $0.05 ; \mathrm{PAS}_{\mathrm{CON}}, 1.01 \pm 0.06$; all $\left.p>0.05\right)$. Furthermore, peak accelerations before motor practice (time point $\mathrm{B} 1$ ) were not different across PAS conditions $\left(\mathrm{PAS}_{\mathrm{LTP}}, 13.24 \pm 1.57 \mathrm{~m} \cdot \mathrm{s}^{-2}\right.$; $\left.\mathrm{PAS}_{\mathrm{LTD}}, 11.67 \pm 1.10 \mathrm{~m} \cdot \mathrm{s}^{-2} ; \mathrm{PAS}_{\mathrm{CON}}, 13.75 \pm 1.49 \mathrm{~m} \cdot \mathrm{s}^{-2}\right)$ and, therefore, cannot account for the differential PAS effects on motor learning (see below). 
PAS effects on peak acceleration during motor practice

An rmANOVA revealed significant effects of PAS condition $\left(F_{(2,16)}=10.06, p=\right.$ $0.0015)$, time $\left(F_{(29,232)}=17.77, p<\right.$ $0.0001)$, and the interaction of PAS condition and time $\left(F_{(58,464)}=2.18, p<0.0001\right)$ on the normalized peak acceleration of the trained movement $\left(\mathrm{ACC}_{\mathrm{MP}} / \mathrm{ACC}_{\mathrm{B} 1}\right.$, $\mathrm{AC}$ $\mathrm{C}_{\mathrm{MP}}$ binned in $1 \mathrm{~min}$ periods over the $2 \times$ 15 min of motor practice) (Fig. 3a). Post hoc testing showed that the effect of PAS condition was explained by PAS $_{\text {LTD }}$ inducing a stronger increase in peak acceleration compared with $\mathrm{PAS}_{\mathrm{CON}}(p=0.0004)$ and $\operatorname{PAS}_{\text {LTP }}(p=0.034)$, and PAS LTP $_{\text {inducing }}$ a stronger increase than $\operatorname{PAS}_{\mathrm{CON}}(p=$ 0.045) (Fig. 3a).

\section{PAS effects on peak acceleration after motor practice}

After the end of motor practice, normalized peak acceleration $\left(\mathrm{ACC}_{\mathrm{P}} / \mathrm{ACC}_{\mathrm{B} 1}\right)$ remained significantly affected by PAS condition $\left(F_{2,16}=6.63, p=0.008\right)$, time $\left(F_{3,24}\right.$ $=17.21, p<0.0001)$, and the interaction between PAS condition and time $\left(F_{6,48}=\right.$ 2.46, $p=0.037$ ) (Fig. 4a). Post hoc testing revealed that normalized peak acceleration was significantly larger after $\mathrm{PAS}_{\mathrm{LTD}}$ than after $\operatorname{PAS}_{\mathrm{CON}}(p=0.002)$, whereas the other comparisons showed only nonsignificant trends toward $\mathrm{PAS}_{\mathrm{LTD}}>\mathrm{PAS}_{\mathrm{LTP}}$ $(p=0.08)$ and $\mathrm{PAS}_{\mathrm{LTP}}>\mathrm{PAS}_{\mathrm{CON}}(p=$ 0.08 ) (Fig. 4a). When peak accelerations in the PAS $_{\text {LTP }}$ and PAS LTD $_{\text {conditions were }}$ normalized by peak acceleration in the PAS $_{\mathrm{CON}}$ condition, there was no longer any effect of PAS condition, time, or the interaction between PAS condition and time (Fig. $4 b$ ). However, one-sample $t$ tests revealed that peak acceleration normalized by the peak acceleration in the $\mathrm{PAS}_{\mathrm{CON}}$ condition was $>1.0$ at all time points (P2$\mathrm{P} 5$, all $p<0.05$ ) in the $\mathrm{PAS}_{\mathrm{LTD}}$ condition, whereas this was not the case at any of the time points in the PAS $_{\mathrm{LTP}}$ condition, indicating that practice-dependent plasticity was enhanced after PAS $_{\text {LTD }}$ but not PAS $_{\text {LTP }}$ when compared with PAS $_{\text {CON }}$ (Fig. 4b).

\section{PAS effects on coefficient of variation of} peak acceleration

RmANOVA revealed a significant effect of time on the coefficient of variation of peak acceleration during the two blocks of motor practice $\left(F_{(29,232)}=5.75, p<0.0001\right)$, whereas the factors PAS condition $\left(F_{(2,8)}=\right.$ $0.13, p=0.88)$ and the interaction between PAS condition and time $\left(F_{(58,464)}=0.89, p=0.71\right)$ were not significant (Fig. $5 a$ ). The effect of time was explained by a steady nonlinear decrease of trial-by-trial variability along the course of practice. a

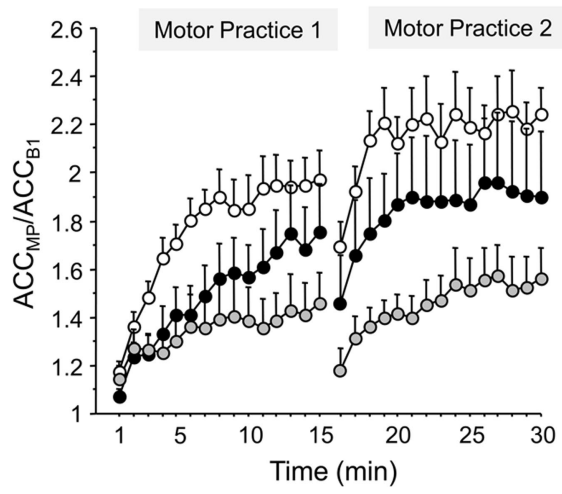

$\boldsymbol{b}$

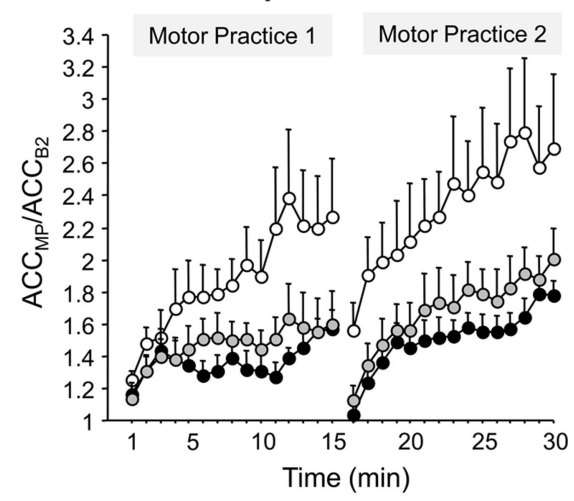

Figure 3. Effects of PAS on learning during motor practice. Increase in peak ACC of the trained thumb flexion movement in experiment $1(\boldsymbol{a})$ and experiment $2(\boldsymbol{b})$ during two blocks of 15 min motor practice (MP) normalized to baseline peak acceleration before practice (experiment 1: $\mathrm{ACC}_{\mathrm{MP}} / \mathrm{ACC}_{\mathrm{B} 1}$; experiment 2: $\mathrm{ACC}_{\mathrm{MP}} / \mathrm{ACC}_{\mathrm{B} 2}$ ) when preceded by $\mathrm{PAS}_{\mathrm{LTP}}$ (black circles), $\mathrm{PAS}_{\mathrm{LTD}}$ (white circles), or PAS ${ }_{\text {CoN }}$ (gray circles). $A C_{M P}$ data are binned in 1 min steps and are means of nine subjects; error bars are 1 SEM. Note that in experiment $1(\boldsymbol{a}), \mathrm{PAS}_{\mathrm{LTD}}$ and $\mathrm{PAS} \mathrm{S}_{\mathrm{LTP}}$ result in enhancement of learning compared with $\mathrm{PAS}_{\mathrm{CON}}$, whereas in experiment 2 (b), PAS $_{\text {LTD }}$ results in enhancement but PAS $_{\text {LTP }}$ in a trend toward depression.

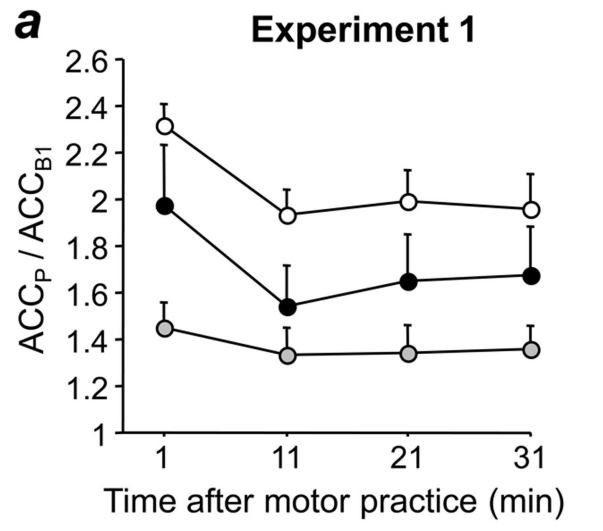

C

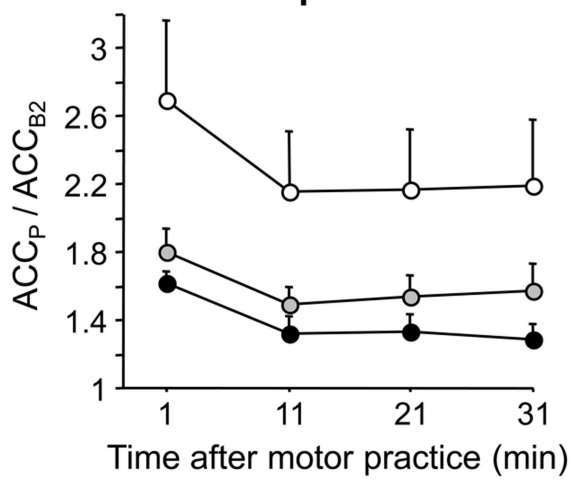

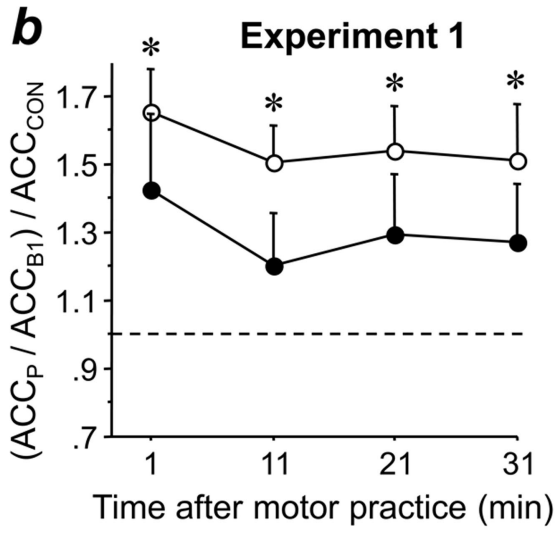

d Experiment 2

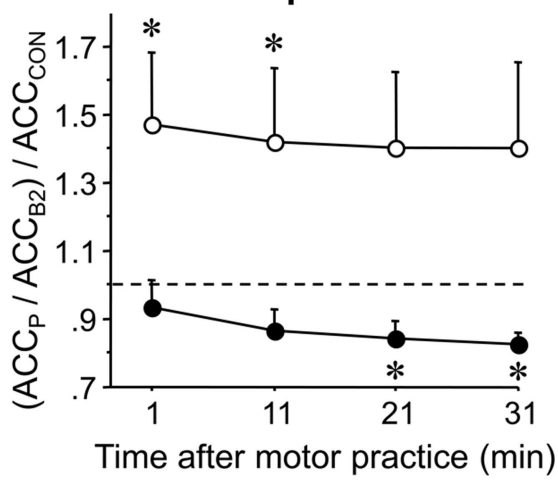

Figure 4. Effects of PAS on learning after the end of motor practice. Change in peak ACC of the trained thumb flexion movement in experiment 1 ( $\boldsymbol{a}$ ) and experiment 2 (c) after the end of practice at time points P2-P5 (1, 11, 21, and 31 min after end of practice, respectively) normalized to peak acceleration immediately before practice (experiment $1, A C C_{P} / A C C_{B 1}$; $\operatorname{experiment} 2, A C C_{P} / A C C_{B 2}$ ) when preceded by PAS $_{\text {LTP }}$ (black circles), PAS $_{\text {LTD }}$ (white circles), or PAS ${ }_{C O N}$ (gray circles). Same data in $\boldsymbol{b}$ and $\boldsymbol{d}$, but peak acceleration is normalized to peak acceleration in the $P A S_{C O N}$ condition. All data are means of nine subjects; error bars are $1 S E M$. Asterisks indicate significant difference from 1 (1-sample $t$ tests, $p<0.05$ ). Note that PAS ${ }_{\text {LTD }}$ led to enhancement of learning in both

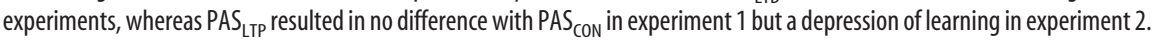

\section{Experiment 2}

PAS effects on MEP amplitude

RmANOVA showed, immediately after paired associative stimulation (time point B1), a significant effect of PAS condition $\left(F_{(2,8)}\right.$ 
a

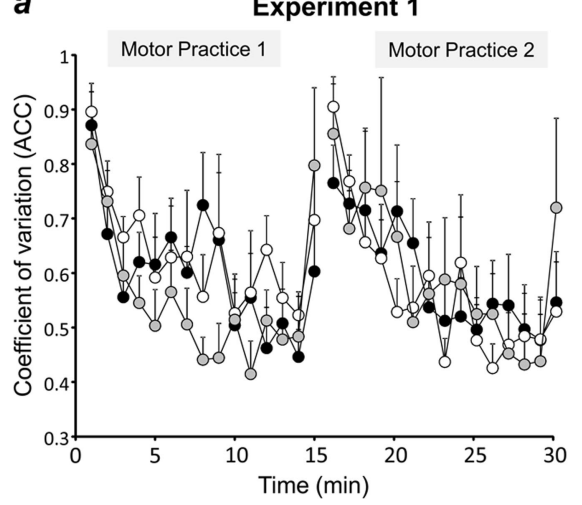

b

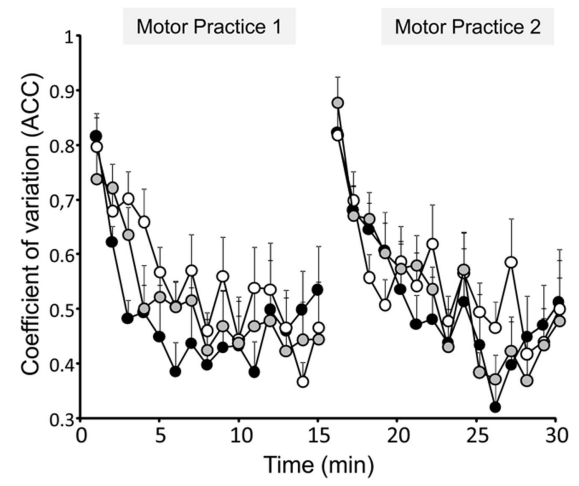

Figure 5. Effects of PAS on learning strategy. Trial-by-trial variability of peak acceleration in experiment 1 ( $\boldsymbol{a}$ ) and experiment 2 (b) during two blocks of 15 min motor practice when preceded by PAS LTP $_{\text {(black circles), } \text { PAS }_{\text {LTD }} \text { (white circles), or PAS }}$ (gray circles), expressed by the coefficient of variation of peak acceleration (for details, see Materials and Methods). All data are binned in 1 min steps and are means of nine subjects; error bars are 1SEM. Note that learning strategy was not different across the three PAS conditions.

$=12.87, p=0.0025)$, and post hoc testing revealed that $\mathrm{PAS}_{\mathrm{LTP}}$ resulted in a significant increase in MEP amplitude $\left(\mathrm{MEP}_{\mathrm{B} 1} /\right.$ $\left.\mathrm{MEP}_{\mathrm{B} 0}: 1.40 \pm 0.16, t=2.49, p=0.038\right) ; \mathrm{PAS}_{\mathrm{LTD}}$ resulted in a significant MEP decrease $(0.70 \pm 0.06, t=-4.72, p=0.0015)$, whereas $\mathrm{PAS}_{\mathrm{CON}}$ had no significant effect $(0.89 \pm 0.06, p>0.05)$ (Fig. 2b). MEP amplitudes at baseline (time point B0) were not different across PAS conditions and, therefore, cannot account for the different PAS effects $\left(\mathrm{PAS}_{\mathrm{LTP}}, 1.10 \pm 0.07 \mathrm{mV}\right.$; PAS $\mathrm{LTD}_{\mathrm{LT}}$, $\left.1.17 \pm 0.08 \mathrm{mV} ; \mathrm{PAS}_{\mathrm{CON}}, 1.10 \pm 0.09 \mathrm{mV}\right)$. Ninety minutes after PAS (time point B2), rmANOVA no longer revealed an effect of PAS condition $\left(F_{(2,8)}=1.83, p=0.19\right)$ (Fig. $\left.2 c\right)$.

\section{PAS effects on peak acceleration before motor practice}

None of the PAS conditions exerted any significant effect on the peak acceleration of thumb flexion movement before motor practice, either immediately after PAS at time point $\mathrm{B} 1\left(\mathrm{ACC}_{\mathrm{B} 1} /\right.$ ACC $_{\text {B0 }}$, PAS $_{\text {LTP }}: 0.92 \pm 0.04$, PAS $_{\text {LTD }}: 1.01 \pm 0.05$, PAS $_{\mathrm{CON}}$ : $1.07 \pm 0.05$, all $p>0.05)$ or 90 min later at time point $\mathrm{B} 2\left(\mathrm{ACC}_{\mathrm{B} 2} /\right.$ $\mathrm{ACC}_{\mathrm{B} 0}, \mathrm{PAS}_{\mathrm{LTP}}: 0.89 \pm 0.07$ PAS $_{\mathrm{LTD}}: 0.93 \pm 0.06 \mathrm{PAS}_{\mathrm{CON}}$ : $0.90 \pm 0.06$; all $p>0.05$ ). Furthermore, peak accelerations immediately before motor practice (time point B2) were not different across PAS conditions $\left(\mathrm{PAS}_{\mathrm{LTP}}: 15.80 \pm 1.29 \mathrm{~m} \cdot \mathrm{s}^{-2}\right.$; $\mathrm{PAS}_{\mathrm{LTD}}$ : $\left.14.60 \pm 2.22 \mathrm{~m} \cdot \mathrm{s}^{-2} ; \mathrm{PAS}_{\mathrm{CON}}: 16.09 \pm 2.12 \mathrm{~m} \cdot \mathrm{s}^{-2}\right)$ and, therefore, cannot account for the differential PAS effects on practicedependent plasticity (see below).

\section{PAS effects on peak acceleration during motor practice}

An rmANOVA revealed significant effects of PAS condition $\left(F_{2,16}\right.$ $=4.04, p=0.039)$, time $\left(F_{(29,232)}=13.16, p<0.0001\right)$ and the interaction of PAS condition and time $\left(F_{(58,464)}=2.30, p<\right.$ $0.0001)$ on the normalized peak acceleration on the normalized peak acceleration of the trained movement $\left(\mathrm{ACC}_{\mathrm{MP}} / \mathrm{ACC}_{\mathrm{B} 1}, \mathrm{AC}-\right.$ $\mathrm{C}_{\mathrm{MP}}$ binned in $1 \mathrm{~min}$ periods over the $2 \times 15 \mathrm{~min}$ of motor practice) (Fig. $3 b)$. Post hoc testing showed that the effect of PAS condition was explained by $\mathrm{PAS}_{\mathrm{LTD}}$ inducing a stronger increase in peak acceleration compared with $\operatorname{PAS}_{\mathrm{CON}}(p=0.049)$ and PAS $_{\text {LTP }}(p=0.016)$, whereas PAS LTP $_{\text {and PAS }}$ CON did not result in different increases in peak acceleration $(p>0.05)$ (Fig. $3 b)$.

\section{PAS effects on peak acceleration after motor practice}

After the end of motor practice, normalized peak acceleration $\left(\mathrm{ACC}_{\mathrm{P}} / \mathrm{ACC}_{\mathrm{B} 2}\right)$ remained significantly affected by PAS condition $\left(F_{(2,16)}=3.97, p=0.04\right)$ and time $\left(F_{(3,24)}=9.75, p=0.0002\right)$, whereas the interaction between PAS condition and time was not significant (Fig. 4c). Post hoc testing revealed that normalized peak acceleration was significantly larger after PAS $_{\mathrm{LTD}}$ than after $\operatorname{PAS}_{\mathrm{LTP}}(p=0.016)$ and $\mathrm{PAS}_{\mathrm{CON}}$ $(p=0.05)$, whereas peak acceleration after $\mathrm{PAS}_{\mathrm{LTP}}$ and $\mathrm{PAS}_{\mathrm{CON}}$ were not different (Fig. 4c). When peak accelerations in the

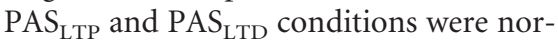
malized by peak acceleration in the PASCON condition, the effect of PAS condition was significant $\left(F_{(1,8)}=6.19, p=0.038\right)$, whereas time and the interaction between PAS condition and time were not (Fig. $4 d$ ). One-sample $t$ tests revealed that peak acceleration normalized by acceleration in the $\mathrm{PAS}_{\mathrm{CON}}$ condition was $>1.0$ at time points $\mathrm{P} 2$ and $\mathrm{P} 3$ in the $\mathrm{PAS}_{\mathrm{LTD}}$ condition, but $<1.0$ at time points $\mathrm{P} 4$ and $\mathrm{P} 5$ in the PAS $_{\text {LTP }}$ condition $(p<0.05)$, indicating that practice-dependent plasticity, was significantly enhanced after PAS $_{\text {LTD }}$ but suppressed after PAS LTP $_{\text {when compared with PAS }}$ CON (Fig. 4d).

\section{PAS effects on coefficient of variation of peak acceleration}

RmANOVA revealed a significant effect of time on the coefficient of variation of peak acceleration during the two blocks of motor practice $\left(F_{(29,232)}=8.79, p<0.0001\right)$, whereas the factors PAS condition $\left(F_{(2,8)}=0.86, p=0.44\right)$ and the interaction between PAS condition and time $\left(F_{(58,464)}=0.93, p=0.63\right)$ were not significant (Fig. $5 b$ ). The effect of time was explained by a steady nonlinear decrease of trial-by-trial variability along the course of practice.

\section{Discussion}

The present experiments show that PAS significantly modulates the extent of subsequent learning of fastest possible simple finger movements. PAS was chosen among many other available brain stimulation protocols because it is similar to stimulation protocols in slices and neuronal cultures, which induce bidirectional spike-timing-dependent synaptic plasticity (Markram et al., 1997; Dan and Poo, 2004; Caporale and Dan, 2008). PAS has been investigated extensively in human sensorimotor cortex and is capable of inducing LTP-like and LTD-like plasticity (Ziemann et al., 2008). Experiments 1 and 2 replicate previous findings that $\mathrm{PAS}_{\text {LTP }}$ increases M1 excitability, as measured by MEP amplitude, whereas $\mathrm{PAS}_{\mathrm{LTD}}$ induces a decrease (Stefan et al., 2000; Wolters et al., 2003; Ziemann et al., 2004; Müller et al., 2007; Rosenkranz et al., 2007). In addition, experiment 2 is in line with previous reports that these changes decay within 90 min or less (Stefan et al., 2000; Wolters et al., 2003). Finally, confirming one previous study (Stefan et al., 2000), $\mathrm{PAS}_{\mathrm{CON}}$ at an interstimulus interval of $100 \mathrm{~ms}$ between median nerve stimulation and TMS did not induce overt changes in M1 excitability and, therefore, can be considered an excellent control condition because identical physical stimuli are used as in the PAS ${ }_{\text {LTP }}$ and PAS $\mathrm{LTD}_{\text {LT }}$ conditions. Rapid simple finger movements were selected for practice because ballistic movements are encoded in M1 (HeppReymond, 1988; Ashe and Georgopoulos, 1994). In addition, two previous studies that had examined the interactions between motor learning and subsequent PAS-induced M1 plasticity used practice of a rapid finger movement (Ziemann et al., 2004; Rosenkranz et al., 2007). Both demonstrated a homeostatic interaction, i.e., the motor practice depressed subsequent PAS- 
induced LTP-like plasticity but enhanced PAS-induced LTD-like plasticity. These findings pertain directly to the present experiments where the order of motor practice and PAS was simply reversed.

\section{Experiment 1}

If motor practice immediately followed PAS then the observed interactions were only in part homeostatic (enhancement of motor learning after $\mathrm{PAS}_{\mathrm{LTD}}$ ) but in part nonhomeostatic (enhancement of motor learning after PAS ${ }_{\text {LTP }}$, although to a lesser extent than after PAS $_{\text {LTD }}$ ). The homeostatic interaction is in accord with the previously observed interactions between motor practice and subsequent PAS-induced M1 plasticity (Ziemann et al., 2004; Stefan et al., 2006; Rosenkranz et al., 2007) and between two brain stimulation plasticity protocols applied in close succession (Iyer et al., 2003; Lang et al., 2004; Siebner et al., 2004; Müller et al., 2007). One influential model to account for homeostatic metaplasticity is bidirectional synaptic plasticity (Bienenstock et al., 1982). The Bienenstock-Cooper-Munro (BCM) model proposes an activity-dependent-sliding threshold for LTP induction at single synapses, which is based on rapid changes in NMDA receptor subunit composition (Philpot et al., 2007). Although the nature of our noninvasive studies at the systems level of human M1 clearly excludes firm conclusions as to the molecular mechanisms of the observed homeostatic interaction between PAS $\mathrm{LTD}_{\mathrm{LT}}$ and subsequent learning, it is fully compatible with the BCM model because the interaction developed rapidly and involved NMDA receptor-dependent LTD-like plasticity (Wolters et al., 2003).

Why then did PAS ${ }_{\text {LTP }}$ and subsequent learning interact in a nonhomeostatic manner? An intriguing possible explanation is that the brain possesses powerful mechanisms, which preserve information encoded by LTP from erasure by immediately subsequent LTD. One such recently described mechanism is based on inhibition of glycogen synthase kinase- 3 by NMDA receptordependent LTP, which results in an $\sim 60$ min lasting blockade of subsequent NMDA receptor-dependent LTD induction because expression of LTD requires a high level of glycogen synthase kinase-3 activity (Peineau et al., 2007). The data of experiment 1 are consistent with similar nonhomeostatic interactions that occurred when excitability-increasing anodal transcranial direct current stimulation was immediately followed by PAS $_{\text {LTP }}$ (Nitsche et al., 2007) or visuo-motor learning (Antal et al., 2008).

Blockade of LTD would not be sufficient by itself, however, to explain why motor learning was enhanced immediately after $\mathrm{PAS}_{\text {LTP }}$ when compared with learning after PAS $\mathrm{CON}_{\text {. This re- }}$ quires the assumption of a facilitating interaction. Several studies in mice and rat hippocampus showed that saturated LTP occludes subsequent learning (Castro et al., 1989; Moser et al., 1998; Gruart et al., 2006; Madroñal et al., 2007). In contrast, nonsaturated LTP can facilitate subsequent learning (Berger, 1984; Jeffery and Morris, 1993; Blank et al., 2002), most likely through activation of calcium/calmodulin-dependent protein kinase II and other downstream mechanisms of central importance for enhancement and persistence of LTP and learning (Lisman et al., 2002; Barria and Malinow, 2005; Merrill et al., 2005). PAS $_{\text {LTP }}$ in the present experiments likely was nonsaturated because a high level of sensorimotor attention toward the stimulated hand, a condition that enhances PAS $_{\text {LTP }}$ effect size (Stefan et al., 2004), was deliberately not requested. In summary, interplay of two processes, LTP-induced blockade of subsequent LTD and nonsaturated LTP-induced facilitation of learning may explain why PAS $_{\text {LTP }}$ facilitated motor learning in experiment 1.
Still, the question may arise, why PAS $_{\text {LTP }}$ and motor practice homeostatically depressed immediately subsequent $\mathrm{PAS}_{\mathrm{LTP}^{-}}$ induced LTP-like plasticity in previous studies (Ziemann et al., 2004; Stefan et al., 2006; Müller et al., 2007; Rosenkranz et al., 2007). A straightforward explanation for this difference is that motor learning, even of simple finger movements, will involve more extensive neuronal circuits than PAS, which induces inputspecific plasticity only in the motor cortical representation targeted by stimulation (Stefan et al., 2000). Therefore, it is likely that motor learning and PAS can saturate LTP in the PAS circuitry, whereas PAS cannot saturate LTP in the learning circuitry.

\section{Experiment 2}

Ninety minutes after PAS, the interactions with subsequent motor learning were fully homeostatic, i.e., $\mathrm{PAS}_{\mathrm{LTD}}$ resulted in facilitation and $\mathrm{PAS}_{\mathrm{LTP}}$ in depression of learning. These findings demonstrate that the interval between brain stimulation and learning is of crucial importance to determine the direction of the interaction. The switch from a nonhomeostatic to a homeostatic interaction between PAS $_{\text {LTP }}$ and learning may be explained by initial masking of the homeostatic interaction by LTP-induced blockade of LTD (experiment 1). Homeostatic metaplasticity becomes visible only after this blockade has decayed. Necessary preconditions for this interpretation are (1) that the duration of LTP-induced blockade of LTD is $<90 \mathrm{~min}$ and (2) that the duration of homeostatic metaplasticity is at least $90 \mathrm{~min}$. Both preconditions are supported by experimental data in rat hippocampus where LTP-induced blockade of LTD lasts $<60$ min (Peineau et al., 2007) and homeostatic suppression of LTP after conditioning LTP induction lasts up to several days (Abraham et al., 2001).

Another important issue is the dissociation between corticomotoneuronal excitability as measured by the MEP amplitude and modulation of motor learning. Experiment 2 clearly showed that the PAS-induced changes in MEP amplitude had fully decayed after 90 min (Fig. 2c), whereas PAS still exerted significant effects on subsequent motor learning. This observation is in agreement with studies in rat hippocampus (Huang et al., 1992) and human motor cortex (Hamada et al., 2008) which demonstrated homeostatic metaplasticity even in the absence of altered synaptic excitability by the conditioning stimulation. Furthermore, this dissociation is consistent with the BCM model of bidirectional synaptic plasticity which proposes changes in the history of postsynaptic activity but not necessarily induction of synaptic plasticity as the determinant of homeostatic metaplasticity (Bienenstock et al., 1982). In experiment 2, it can be assumed that PAS $_{\text {LTP }}$ resulted in increased firing activity of motor cortical neurons through initially increased excitability, whereas PAS $_{\text {LTD }}$ led to decreased firing activity, and that these alterations in activity contributed to the homeostatic interactions between PAS and learning. Together, this critically challenges the common use of MEP amplitude as a surrogate marker for capacity and extent of behavioral relevant plasticity in human motor cortex.

Finally, analysis of the learning strategy revealed that subjects learned by using the experience gained from the previous trials, as expressed by a steady decrease of the coefficient of variation of trial-to-trial peak acceleration over the duration of motor practice (Fig. 5). Importantly, the different PAS conditions had no effect on this behavior, and therefore, it can be concluded that the differential effects of PAS on the extent and direction of motor learning were not accounted for by modified learning strategy. 


\section{Significance}

This study demonstrated that paired associative brain stimulation can significantly modulate motor learning in healthy subjects. These findings are potentially relevant for enhancement of motor relearning by brain stimulation in defined neurological patients, for instance after cerebral stroke. One currently influential concept is to pair motor practice with brain stimulationinduced increase in excitability of the training motor cortex of the lesioned hemisphere (Ward and Cohen, 2004; Ziemann, 2005; Hummel and Cohen, 2006; Talelli and Rothwell, 2006). Although the present study by no means disqualifies that concept, it raises the possibility that pairing of $\mathrm{PAS}_{\mathrm{LTD}}$, an excitability-decreasing manipulation, with subsequent motor practice may result in even more powerful facilitation of learning through mechanisms of homeostatic metaplasticity. Still, the link between modulation of motor learning and recovery of function after brain lesion has to be demonstrated in appropriately designed clinical studies.

\section{References}

Abbott LF, Nelson SB (2000) Synaptic plasticity: taming the beast. Nat Neurosci [Suppl 3]:1178-1183.

Abraham WC, Bear MF (1996) Metaplasticity: the plasticity of synaptic plasticity. Trends Neurosci 19:126-130.

Abraham WC, Mason-Parker SE, Bear MF, Webb S, Tate WP (2001) Heterosynaptic metaplasticity in the hippocampus in vivo: a BCM-like modifiable threshold for LTP. Proc Natl Acad Sci U S A 98:10924-10929.

Agostino R, Iezzi E, Dinapoli L, Gilio F, Conte A, Mari F, Berardelli A (2007) Effects of $5 \mathrm{~Hz}$ subthreshold magnetic stimulation of primary motor cortex on fast finger movements in normal subjects. Exp Brain Res 180:105-111.

Agostino R, Iezzi E, Dinapoli L, Suppa A, Conte A, Berardelli A (2008) Effects of intermittent theta-burst stimulation on practice-related changes in fast finger movements in healthy subjects. Eur J Neurosci 28:822-828.

Antal A, Begemeier S, Nitsche MA, Paulus W (2008) Prior state of cortical activity influences subsequent practicing of a visuomotor coordination task. Neuropsychologia 46:3157-3161.

Ashe J, Georgopoulos AP (1994) Movement parameters and neural activity in motor cortex and area 5. Cereb Cortex 4:590-600.

Barria A, Malinow R (2005) NMDA receptor subunit composition controls synaptic plasticity by regulating binding to CaMKII. Neuron 48:289-301.

Berger TW (1984) Long-term potentiation of hippocampal synaptic transmission affects rate of behavioral learning. Science 224:627-630.

Bienenstock EL, Cooper LN, Munro PW (1982) Theory for the development of neuron selectivity: orientation specificity and binocular interaction in visual cortex. J Neurosci 2:32-48.

Blank T, Nijholt I, Eckart K, Spiess J (2002) Priming of long-term potentiation in mouse hippocampus by corticotropin-releasing factor and acute stress: implications for hippocampus-dependent learning. J Neurosci 22:3788-3794.

Boggio PS, Castro LO, Savagim EA, Braite R, Cruz VC, Rocha RR, Rigonatti SP, Silva MT, Fregni F (2006) Enhancement of non-dominant hand motor function by anodal transcranial direct current stimulation. Neurosci Lett 404:232-236.

Caporale N, Dan Y (2008) Spike timing-dependent plasticity: a Hebbian learning rule. Annu Rev Neurosci 31:25-46.

Castro CA, Silbert LH, McNaughton BL, Barnes CA (1989) Recovery of spatial learning deficits after decay of electrically induced synaptic enhancement in the hippocampus. Nature 342:545-548.

Cooke SF, Bliss TV (2006) Plasticity in the human central nervous system. Brain 129:1659-1673.

Dan Y, Poo MM (2004) Spike timing-dependent plasticity of neural circuits. Neuron 44:23-30.

Di Lazzaro V, Oliviero A, Pilato F, Saturno E, Dileone M, Mazzone P, Insola A, Tonali PA, Rothwell JC (2004) The physiological basis of transcranial motor cortex stimulation in conscious humans. Clin Neurophysiol 115:255-266.

Di Lazzaro V, Ziemann U, Lemon RN (2008) State of the art: physiology of transcranial motor cortex stimulation. Brain Stimulation 1:345-362.

Gruart A, Muñoz MD, Delgado-García JM (2006) Involvement of the CA3-
CA1 synapse in the acquisition of associative learning in behaving mice J Neurosci 26:1077-1087.

Hamada M, Terao Y, Hanajima R, Shirota Y, Nakatani-Enomoto S, Furubayashi T, Matsumoto H, Ugawa Y (2008) Bidirectional long-term motor cortical plasticity and metaplasticity induced by quadripulse transcranial magnetic stimulation. J Physiol 586:3927-3947.

Hepp-Reymond M-C (1988) Functional organization of motor cortex and its participation in voluntary movements. In: Comparative primate biology (Seklis HD, Erwin J, eds), pp 501-624. New York: Liss.

Huang YY, Colino A, Selig DK, Malenka RC (1992) The influence of prior synaptic activity on the induction of long-term potentiation. Science 255:730-733.

Hummel FC, Cohen LG (2006) Non-invasive brain stimulation: a new strategy to improve neurorehabilitation after stroke? Lancet Neurol 5:708-712.

Iyer MB, Schleper N, Wassermann EM (2003) Priming stimulation enhances the depressant effect of low-frequency repetitive transcranial magnetic stimulation. J Neurosci 23:10867-10872.

Jeffery KJ, Morris RG (1993) Cumulative long-term potentiation in the rat dentate gyrus correlates with, but does not modify, performance in the water maze. Hippocampus 3:133-140.

Krakauer JW (2006) Motor learning: its relevance to stroke recovery and neurorehabilitation. Curr Opin Neurol 19:84-90.

Kujirai K, Kujirai T, Sinkjaer T, Rothwell JC (2006) Associative plasticity in human motor cortex during voluntary muscle contraction. J Neurophysiol 96:1337-1346.

Kuo MF, Unger M, Liebetanz D, Lang N, Tergau F, Paulus W, Nitsche MA (2008) Limited impact of homeostatic plasticity on motor learning in humans. Neuropsychologia 46:2122-2128.

Lang N, Siebner HR, Ernst D, Nitsche MA, Paulus W, Lemon RN, Rothwell JC (2004) Preconditioning with transcranial direct current stimulation sensitizes the motor cortex to rapid-rate transcranial magnetic stimulation and controls the direction of after-effects. Biol Psychiatry 56:634-639.

Lisman J, Schulman H, Cline H (2002) The molecular basis of CaMKII function in synaptic and behavioural memory. Nat Rev Neurosci 3:175-190.

Madroñal N, Delgado-García JM, Gruart A (2007) Differential effects of long-term potentiation evoked at the CA3 CA1 synapse before, during, and after the acquisition of classical eyeblink conditioning in behaving mice. J Neurosci 27:12139-12146.

Markram H, Lübke J, Frotscher M, Sakmann B (1997) Regulation of synaptic efficacy by coincidence of postsynaptic APs and EPSPs. Science 275:213-215.

Merrill MA, Chen Y, Strack S, Hell JW (2005) Activity-driven postsynaptic translocation of CaMKII. Trends Pharmacol Sci 26:645-653.

Monfils MH, Teskey GC (2004) Skilled-learning-induced potentiation in rat sensorimotor cortex: a transient form of behavioural long-term potentiation. Neuroscience 125:329-336.

Moser EI, Krobert KA, Moser MB, Morris RGM (1998) Impaired spatial learning after saturation of long-term potentiation. Science 281:2038-2042.

Muellbacher W, Ziemann U, Boroojerdi B, Cohen L, Hallett M (2001) Role of the human motor cortex in rapid motor learning. Exp Brain Res 136:431-438.

Muellbacher W, Ziemann U, Wissel J, Dang N, Kofler M, Facchini S, Boroojerdi B, Poewe W, Hallett M (2002) Early consolidation in human primary motor cortex. Nature 415:640-644.

Müller JF, Orekhov Y, Liu Y, Ziemann U (2007) Homeostatic plasticity in human motor cortex demonstrated by two consecutive sessions of paired associative stimulation. Eur J Neurosci 25:3461-3468.

Nitsche MA, Schauenburg A, Lang N, Liebetanz D, Exner C, Paulus W, Tergau F (2003) Facilitation of implicit motor learning by weak transcranial direct current stimulation of the primary motor cortex in the human. J Cogn Neurosci 15:619-626.

Nitsche MA, Roth A, Kuo MF, Fischer AK, Liebetanz D, Lang N, Tergau F, Paulus W (2007) Timing-dependent modulation of associative plasticity by general network excitability in the human motor cortex. J Neurosci 27:3807-3812.

Oldfield RC (1971) The assessment and analysis of handedness: the Edinburgh inventory. Neuropsychologia 9:97-113.

Peineau S, Taghibiglou C, Bradley C, Wong TP, Liu L, Lu J, Lo E, Wu D, Saule E, Bouschet T, Matthews P, Isaac JT, Bortolotto ZA, Wang YT, Col- 
lingridge GL (2007) LTP inhibits LTD in the hippocampus via regulation of GSK3beta. Neuron 53:703-717.

Philpot BD, Cho KK, Bear MF (2007) Obligatory role of NR2A for metaplasticity in visual cortex. Neuron 53:495-502.

Ridding MC, Taylor JL (2001) Mechanisms of motor-evoked potential facilitation following prolonged dual peripheral and central stimulation in humans. J Physiol 537:623-631.

Rioult-Pedotti MS, Friedman D, Hess G, Donoghue JP (1998) Strengthening of horizontal cortical connections following skill learning. Nat Neurosci 1:230-234.

Rioult-Pedotti MS, Friedman D, Donoghue JP (2000) Learning-induced LTP in neocortex. Science 290:533-536.

Rosenkranz K, Kacar A, Rothwell JC (2007) Differential modulation of motor cortical plasticity and excitability in early and late phases of human motor learning. J Neurosci 27:12058-12066.

Sanes JN (2003) Neocortical mechanisms in motor learning. Curr Opin Neurobiol 13:225-231.

Siebner HR, Lang N, Rizzo V, Nitsche MA, Paulus W, Lemon RN, Rothwell JC (2004) Preconditioning of low-frequency repetitive transcranial magnetic stimulation with transcranial direct current stimulation: evidence for homeostatic plasticity in the human motor cortex. J Neurosci 24:3379-3385.

Stefan K, Kunesch E, Cohen LG, Benecke R, Classen J (2000) Induction of plasticity in the human motor cortex by paired associative stimulation. Brain 123:572-584.

Stefan K, Kunesch E, Benecke R, Cohen LG, Classen J (2002) Mechanisms of enhancement of human motor cortex excitability induced by interventional paired associative stimulation. J Physiol 543:699-708.

Stefan K, Wycislo M, Classen J (2004) Modulation of associative human motor cortical plasticity by attention. J Neurophysiol 92:66-72.

Stefan K, Wycislo M, Gentner R, Schramm A, Naumann M, Reiners K, Classen J (2006) Temporary occlusion of associative motor cortical plasticity by prior dynamic motor training. Cereb Cortex 16:376-385.
Talelli P, Rothwell J (2006) Does brain stimulation after stroke have a future? Curr Opin Neurol 19:543-550.

Turrigiano GG, Nelson SB (2004) Homeostatic plasticity in the developing nervous system. Nat Rev Neurosci 5:97-107.

Vines BW, Cerruti C, Schlaug G (2008) Dual-hemisphere tDCS facilitates greater improvements for healthy subjects' non-dominant hand compared to uni-hemisphere stimulation. BMC Neurosci 9:103

Walther M, Kuhnke N, Schessl J, Delvendahl I, Jung N, Kreml D, Ziemann U, Mall V (2008) Deafferentation of neighbouring motor cortex areas does not further enhance saturated practice-dependent plasticity in healthy adults. Clin Neurophysiol 119:886-891.

Ward NS, Cohen LG (2004) Mechanisms underlying recovery of motor function after stroke. Arch Neurol 61:1844-1848.

Wolters A, Sandbrink F, Schlottmann A, Kunesch E, Stefan K, Cohen LG, Benecke R, Classen J (2003) A temporally asymmetric Hebbian rule governing plasticity in the human motor cortex. J Neurophysiol 89:2339-2345.

Ziemann U (2004) TMS and drugs. Clin Neurophysiol 115:1717-1729.

Ziemann U (2005) Improving disability in stroke with RTMS. Lancet Neurol 4:454-455.

Ziemann U, Siebner H (2008) Modifying motor learning through gating and homeostatic metaplasticity. Brain Stimulation 1:60-66.

Ziemann U, Iliæ TV, Iliaæ TV, Pauli C, Meintzschel F, Ruge D (2004) Learning modifies subsequent induction of LTP-like and LTD-like plasticity in human motor cortex. J Neurosci 24:1666-1672.

Ziemann U, Iliæ TV, Jung P (2006) Long-term potentiation (LTP)-like plasticity and learning in human motor cortex-investigations with transcranial magnetic stimulation (TMS). Suppl Clin Neurophysiol 59:19-25.

Ziemann U, Paulus W, Nitsche MA, Pascual-Leone A, Byblow WD, Berardelli A, Siebner HR, Classen J, Cohen LG, Rothwell JC (2008) Consensus: motor cortex plasticity protocols. Brain Stimulation 1:164-182. 